Journal of Research in Technical Careers

May 2017, Vol. 1, No. 1.

(C) Author(s)

\title{
Effects of Integrating Mathematical Concepts into a Nutrition Unit in the Animal Science Curriculum
}

\author{
Andrea R. Gardner, Brian K. Warnick, Rebecca G. Lawver \\ Utah State University
}

\begin{abstract}
Achievement test scores in mathematics have been a concern among educators for many years. Teaching contextualized mathematics has been found to be effective and includes providing a direct application to real-life scenarios rather than teaching linear equations and algebraic principles in isolation. This study measured the effects of integrating mathematical skills in one instructional unit in an animal science curriculum. Students from eight schools participated in the research study. Students completed a pretest measuring their existing mathematical skills and self-efficacy in math. All students were taught a unit of instruction about animal nutrition and feeding. The control group received a typical nutrition unit, and the treatment group received the same unit of instruction with the addition of mathematical skill integration. Following the unit of instruction, students completed a posttest survey, which included a mathematics attitudinal scale, posttreatment self-efficacy scale, and posttreatment mathematics skills questions. No statistically significant difference was found in mathematics selfefficacy or mathematics skills between the control group and treatment. However, results indicated a strong positive relationship between students' mathematics self-efficacy and their mathematics skills. Further, highest level of mathematics courses completed and overall grade point average were statistically significant factors in predicting mathematics selfefficacy.
\end{abstract}

Keywords: agricultural education, academic integration, mathematics

\section{Introduction}

Nationwide, mathematics test scores have dropped and are a subject of concern among teachers, administrators, and even college professors whose students do not have adequate entry-level mathematics scores to be successful in college level mathematics classes after high school (Howard \& Whitaker, 2008). To address this growing concern, educators must determine what motivates students to master and retain mathematical skills and determine what type of pedagogy is most effective. Lewin (2006) reported that a tighter focus on basic mathematics skills was in play and that the "mile wide, inch deep" state standards were forcing elementary and secondary mathematics teachers to teach dozens of mathematics topics too quickly without taking the time for students to truly grasp and master the principles. Similarly, colleges and universities are facing a growing need for remedial mathematics courses in order for their students to be successful in college courses. Evidence also suggests that mathematics requirements actually hinder some students from pursuing a major they would otherwise choose if its mathematics requirements were not so high (Howard \& Whitaker, 2008).
Prior research has indicated that teaching mathematics in its natural context is the most effective method for students to acquire and master true mathematical skills (Stone \& Hansen, 2007). A traditional mathematics classroom teaches mathematics concepts in isolation rather than focusing on contextbased problems integrated into the mathematics curriculum. The traditional approach often consists of a daily routine where the teacher provides a demonstration of a mathematics skill followed by an assignment to practice and memorize the steps of the skill. It also consists of a list of numerical problems to be solved, generally without a context or direct need to solve them. This approach often leads to students who dislike mathematics and are not able to make relevant connections between mathematics and life beyond high school (Lewin, 2006). Stone, Alfeld, and Pearson (2008), citing The National Council of Teachers of Mathematics (2000), reported that student disengagement and lack of interest is a significant factor in low scores on mathematics achievement tests. They also indicated that students typically disengage in the learning process due to difficulty with the subject, lack of support, boredom, or because the topic does not seem relevant to life after high school. 
Journal of Research in Technical Careers

\section{Student Motivation and Self-Efficacy in Mathematics}

Levels of motivation to learn mathematics skills are correlated positively with academic success (Howard \& Whitaker, 2008). Howard and Whitaker (2008) discovered that, "Motivation was the most common reason given as the difference between unsuccessful and successful mathematics skill development” (p. iv). In addition, Howard and Whitaker (2008) found that "when successful, students actually enjoyed learning mathematics and expressed confidence that they would be successful [in future math courses]” (p. iv). Struggling mathematics students report being more motivated to learn when mathematics is applied to their situation and to their prospective vocation. Another method of improving student motivation to learn mathematics principles is to make it directly applicable to the student. One task that must be accomplished to successfully teach mathematics skills is to make mathematics valuable and applicable in the student's life. Howard's and Whitaker's (2008) study indicated that struggling mathematics students do "not see the value of their education for their future or how learning mathematics would apply to their situation, which consequently reinforced the negative attitudes towards having to learn mathematics” (p. 49). Even having a positive attitude toward the subject of mathematics is identified as a factor in successfully learning and mastering mathematical skills. To reinforce and increase efforts in math, students must begin by developing positive self-concepts (Fiore, 1999).

Akinsola and Awofala (2009) researched the effects of personalizing the context through which mathematical principles were taught. Results of their study support the theory that teaching mathematics through a context increases confidence, enjoyment, and learning and that it can be considered a method of increasing self-efficacy in math. Bandura (1977) described self-efficacy as the strength of people's convictions in themselves and their own ability to cope with stress or challenging situations. Efficacy expectations determine how long someone will persist when faced with an obstacle or stressful situation. If their sense of perceived self-efficacy is strong, they will not give up before a concept is mastered. Selfefficacy expectations lead to specific behavior. Behavior leads to an expected outcome, which leads to an actual outcome (Bandura, 1977).

Stevens, Olivarez, Lan, and Tallent-Runnels (2004) identified the primary factor in the development of selfefficacy in mathematics to be a student's prior performance (grades) in mathematics classes. If the student experienced success in prior mathematics classes, they exhibited a higher level of intrinsic motivation to learn additional mathematics skills, which are directly correlated to both mathematics performance and selfefficacy in math. Pajares and Miller (1997) reviewed the method of competency testing to determine if there was a correlation between test format and self-efficacy. There was no significant difference between using a multiple choice formatted test and an open-ended question test format.

\section{Gender Differences in Mathematics Achievement}

Learning strengths and weaknesses have unique trends specific to gender. Historically, boys have outperformed girls in mathematics (McFarland, Benson, \& McFarland, 2011). However, some gender differences associated with performance have narrowed in recent years. In 1992, boys earned average test scores 0.25 standard deviations higher than girls, but by 2010 it was found that, although boys scored higher in mathematics and science and girls scored higher in reading, an average score across the three subjects was basically equal (Pope \& Sydnor, 2010). To add to these findings, there also is a trend showing that women who experienced early success in mathematics performance took more classes in mathematics and science, which led to the likelihood of choosing science and mathematics majors in postsecondary education (Trusty, 2002). Single-gender classes have been studied and discovered that mathematics scores for both boys and girls are higher in single-gender classes than mathematics scores in traditional classes with boys and girls (McFarland et al., 2011). King, Gurian, and Stevens (2010) reported that teacher education and certification programs lack the training teachers need to effectively teach boys and girls according to their strengths. Additionally, Pajares and Miller (1997) found that overall, boys reported a higher level of self-efficacy in math. Boys were also more accurate in predicting their performance than girls.

\section{Academic Integration in Career and Technical Education}

To some, the obvious solution to lagging mathematics performance would be to require more mathematics courses in high school. However, increasing mathematics requirements alone may not be the answer to the problem. Career and Technical Education (CTE) courses focus on students learning specific skills in their area of trade. Core academics and soft skills are embedded naturally and easily within CTE (Tews, 2011). What is learned in a CTE classroom is often specifically and directly applicable to the student's life and potential vocation. Most high school Career and Technical Education (CTE) classes provide a natural bridge between mathematics and its practical application. When mathematical concepts are applied within CTE curricula, students find it more relevant and are more motivated to master the concepts (Stone et al., 2008). An agricultural classroom setting has natural mathematical applications, allowing mathematics principles to be mastered and retained. For example, animal feed and medication 
quantities must be calculated according to the weight of an animal before they are administered, ratios and proportions are calculated in the processing of agricultural products such as ground beef, and genetic inheritance probabilities are determined using mathematical equations. If properly applied to the agricultural curriculum, mathematical principles can be taught and applied to real-life scenarios, allowing students to understand the direct application of the concept.

Students learn mathematics best when they can see the concepts' applications in real-life (Shinn et al., 2003). This type of teaching and learning is typically taught with a direct application to authentic principles rather than to simple facts or memorization. Contextually based teaching and learning is more visual to the learner and can be seen as more than just numbers on a paper. Another way to describe this method of teaching and learning is "curriculum integration." Curricular integration models are methods of pedagogy that do not isolate each subject, but instead integrate them across the curriculum. Stone et al. (2008) stated, “A contextual mathematics approach requires that educators change the way in which they deliver content in order to produce enhanced thinking about and use of mathematics concepts among students” (pp. 771-772). Although most research studies on teaching mathematics in context have shown positive results, in some cases it has been found that students have difficulty transferring the knowledge learned from one context to another (Stone et al., 2008).

CTE classrooms provide a good opportunity to integrate mathematics skills and curriculum with real-life problems in areas of business, family and consumer sciences, agriculture, and other technical skills areas. Stone et al. (2008) stated, "CTE courses have the best potential for demonstrating to students that rigorous math is in fact highly relevant” (p. 791). CTE curriculum with mathematical concepts integrated within the curriculum provide teaching and learning opportunities that incorporate real-world mathematics skills that prepare students for college and careers (Tews, 2011). Stone et al. (2008) investigated the effects of mathematics and CTE integration. Over the course of one year, CTE teachers were paired with mathematics teachers. Together, they created a curriculum map identifying ways to integrate mathematics skills into the CTE curriculum. The results of the study were positive, showing that mathematics and CTE integration could improve traditional mathematics scores and scores on a college placement mathematics test. However, the study also concluded that CTE students' scores on applied mathematics tests did not improve (Stone et al., 2008). Incorporating mathematics skills within a student's area of interest will dramatically increase the retention and understanding of mathematics skills (Tews, 2011).

Parr, Edwards, and Leising (2006) studied mathenhanced curriculum in agriculture classes, focusing on the effects of integrating mathematics in the agricultural power and technology course. This study found that students who experienced the experimental treatment performed better on postsecondary mathematics placement tests. This study supported other theories that, "providing a context in which learning may take place does hold value for improving student comprehension and retention of subject matter" (Parr et al., 2006, p. 89). A study by Young, Edwards, and Leising (2009) focused on discovering if students taught using a math-enhanced agricultural mechanics curriculum gained equivalent technical competence when compared with students in a curriculum without mathematics enhancement. The treatment group received math-enhanced lessons, which were designed specifically to increase the contextually based mathematics, found in the agricultural power and technology curriculum. Results indicated no significant difference in the acquisition of technical skills between students who experienced a math-enhanced curriculum and students who did not receive a math-enhanced curriculum (Young et al., 2009).

\section{Conceptual Model}

Overall, studies have indicated that effective mathematics pedagogy includes applying mathematics principles to real-life situations and making mathematics techniques more visual. Additionally, studies have been conducted about increasing self-efficacy in students and improving student attitudes about math. However, few studies have been conducted measuring the effects of applying mathematics in the agriculture curriculum, and no known studies have researched the motivational and self-efficacy effects of applying mathematical principles in an animal science curriculum. Further assessment of the effects of integrating mathematics in the animal science curriculum is vital and will benefit students and school districts by supporting and teaching the value of cross-curricular education. In the design of the present study, mathematics was integrated into the CTE curriculum following the model of Parr et al. (2006). This model requires that the majority of the lesson be CTE curriculum-based materials with only a small portion of mathematics enhancement. A conceptual model for this study, based on the Parr (et al.) model, is provided in Figure 1.

In 2011, the National Center for Education Statistics reported that only $35 \%$ of eighth graders in Utah scored at or above proficient level. As secondary students continue to struggle with mastering mathematical concepts, effective methods of teaching and reinforcing mathematics skills need to be discovered and implemented. Agricultural education courses, specifically animal science, provide an opportunity for students to apply mathematical concepts using relevant contexts. The perceptions of and performance in mathematics used by animal science students in Utah has never been assessed. 


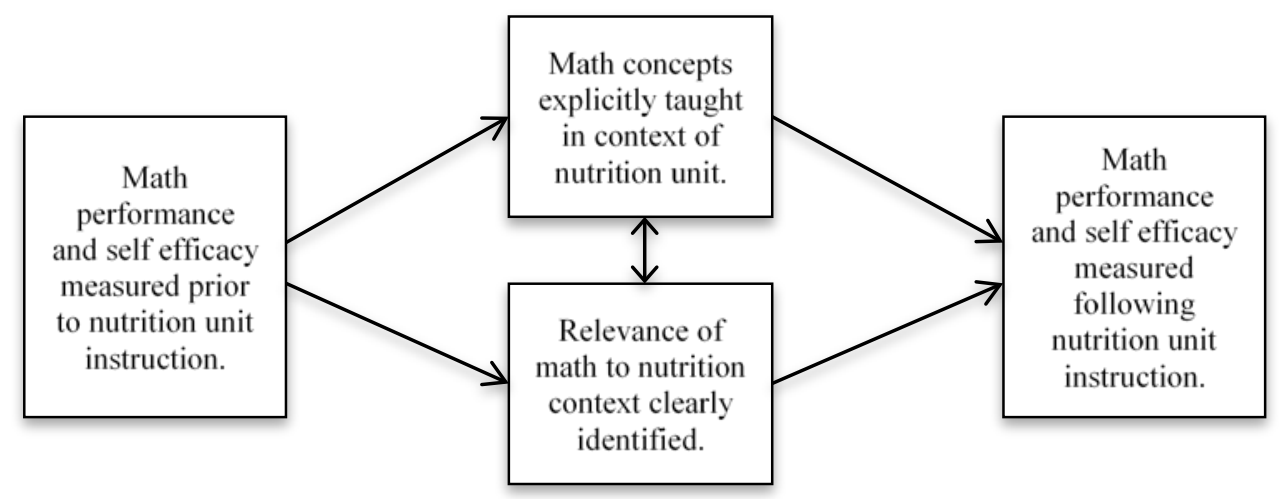

Figure 1. Conceptual model for mathematics performance and self-efficacy related to contextual instruction within an animal science course.

\section{Purpose and Research Questions}

The purpose of this study was to investigate the effect of integrating basic algebra concepts into a nutrition unit in an animal science course on mathematics achievement scores. A secondary purpose of this study was to explore students' attitudes toward and perceived ability to perform mathematics skills when mathematical concepts are integrated into the animal science curriculum. This study is aligned with the National Research Agenda of the American Association for Agricultural Education (Doerfert, 2011) Research Priority Area 5: Efficient and Effective Agricultural Education Programs and specifically addresses the focus area: "Demonstrate the effective integration of STEM (science, technology, engineering and math) into agricultural education programs."

Four research questions guided this study and two null hypotheses were tested. The research questions were: (a) Does the integration of algebra concepts into an animal science instructional unit improve students' ability to complete mathematics problems? (b) Does the integration of algebra concepts into an animal science instructional unit improve students' self-efficacy in math? (c) Is there a relationship between student mathematics scores and their mathematics self-efficacy? and (d) What student characteristics are predictive of mathematics self-efficacy and mathematics performance? The two null hypotheses that were tested were: (a) There will be no significant difference in student mathematics test scores when taught using applications in animal science; and (b) There will be no significant difference in students' perceived ability to master mathematic skills.

The overall goal of this study was to help determine a more effective teaching pedagogy for mathematical skills within the agricultural curriculum, which could result in long-term benefits for students. These potential benefits included improved student grades in high school, improved motivation to master mathematics skills, improved college entrance exam scores, and a more successful transition from high school to post-secondary mathematics class placement.

\section{Methods and Procedures}

This research study utilized a quasi-experimental approach using a Solomon four-group design (Campbell \& Stanley, 1963). The experiment consisted of four randomly assigned groups, which included two control groups and two experimental groups, of high school agriculture students enrolled in animal science courses. This design was selected to minimize threats to internal validity while enhancing external validity. The Solomon four-group design is particularly effective in determining whether the effects of testing influenced the results of the study.

The independent variable in this experiment was the explicit teaching of mathematics concepts within an animal nutrition unit in an animal science course. The dependent variables were the test scores, student attitudes, and perceived ability to master mathematical principles (mathematics self-efficacy). Other extraneous variables included the time of day instruction was given and direct applicability to each participating student. The study evaluated two factors: student motivation and selfefficacy in learning mathematical principles and mathematical test performance.

Eight schools were selected purposely throughout the Utah. Each participating school offered at least two sections of the Utah State Board of Education approved Animal Science I course taught by the same teacher during the last half of the 2012-2013 academic year. One section in each school was randomly assigned as a treatment group and one as a control group. The total number of study participants was 416 (224 treatment; 192 control).

The mathematics performance portion of the preand posttests was developed with a mathematics teacher to ensure the concepts and questions matched 
competencies found on Utah Mathematics Core Competency tests. The instrument used for measuring mathematics performance was reviewed by a panel of experts including secondary mathematics teachers and university teacher educators. The instrument was pilot tested by an animal science class not included in the experiment and by a high school algebra class.

The self-efficacy questionnaire was adapted from the Mathematics Self-Efficacy Scale (MSES; Betz \& Hackett, 1983) with task prompts included based on the input and expertise of high school mathematics teachers and aligned with the mathematics skills outlined in related state standards and objectives. Questions were modified to specifically address the application of mathematics concepts to the animal science context. This self-efficacy instrument was also reviewed by a panel of experts including university teacher educators and was pilot tested with a secondary mathematics class and an animal science class not included in the research study.

The principal at each participating school was contacted prior to the research study to obtain permission. Institutional Review Board approval was obtained and Letters of Information were developed and distributed to students and parents in English and Spanish. The researcher provided training to participating teachers to minimize the effect of the extraneous variable of the teacher. All curriculum including instructional PowerPoint presentations, notes, practice worksheets, and review activities were prepared beforehand and given to each participating teacher. The total instruction time for the entire unit was 5-7 days depending on whether the school had a traditional 5-6 period schedule or an A/B block schedule. The experiment was conducted during the months of February and March, 2013. The pretest was administered randomly to half of the students in each group at least one week prior to the beginning of the unit of instruction. The pretest was not given immediately prior to the unit of instruction in order to avoid biased or conditioned responses. This created a baseline of mathematical knowledge and controlled for outside variables that could impact the final results.

Following the administration of the pretest, all experimental groups received instruction within the designed animal nutrition unit. Providing the manipulation to an experimental group that did not receive the pretest ensured the researcher was measuring a change caused by the manipulation and not by other outside factors. The manipulation included a unit of instruction that focused primarily on an animal science concept that required accurate algebra computing skills to reach mastery levels on the posttest.

After delivery of the instructional unit, the mathematics performance posttest and the mathematics attitude and self-efficacy instruments were given to all of the subjects. The posttest measured students' mathematics ability, perceived mathematics ability, and motivation to learn mathematics principles. Demographic information on all research subjects including grade level, gender, highest completed mathematics class, and grade earned in highest completed mathematics class was collected at the time of the pretest. The data allowed the researcher greater control in the research design and accounted for outliers in the final results. Gathering demographic information allowed the evaluation of correlational patterns associated with the test scores and the students' perceived ability and attitudes towards math.

Research question one was analyzed by summating the correct answers for each student on the mathematics performance posttest. These summated scores were analyzed by using a two-by-two analysis of variance (ANOVA). This allowed for comparisons to be made between and within the four groups and allowed the researcher to accept or reject the null hypothesis. The significance level was set a priori at .05. The data related to research question two was analyzed by summating the scores on the mathematics attitude and mathematics selfefficacy instrument. These summated scores were then treated as interval data and were analyzed using a twoby-two ANOVA with the significance level set a priori at .05. A Pearson product-moment correlation was used to analyze the data related to research question three. Using the Pearson correlation allowed the research to explore the relationships between the mathematics performance variables and the mathematics self-efficacy variables. Question four was analyzed using multiple regression analysis.

\section{Results and Findings}

The total number of animal science student participants was 416 . A post hoc reliability analysis of the survey instrument was performed to determine if the instrument had an acceptable reliability value. Internal consistency was estimated at 0.773 using Cronbach's alpha. A summary of the four respondent groups can be found in Table 1.

The entire research group consisted of 220 males (52.9\%) and 196 females (47.1\%). There were 13 (3.1\%) $9^{\text {th }}$ graders, $124(29.8 \%) 10^{\text {th }}$ graders, $205(49.3 \%) 11^{\text {th }}$ graders, and $74(17.8 \%) 12^{\text {th }}$ graders. Respondents also reported their highest-level mathematics class completed (Table 2).

Students also reported the grade they received in the highest completed mathematics class (Table 3).

Research question one measured the change in preand posttest mathematics scores. There was no statistically significant difference between the mathematics performance pretest of the control group ( $M$ $=5.070, S D=1.760)$ as compared to the mean mathematics performance of the experimental group on the pretest $(M=5.040, S D=1.770), t(154)=0.082, p$ $=.606$ (two-tailed). Therefore, the researcher failed to reject the null hypothesis. There was no statistically significant difference between the mathematics performance posttest of the control group $(M=4.960, S D$ $=2.100$ ), as compared to the mean on the mathematics performance posttest of the experimental group $(M=$ 
Table 1. Description of Research Groups

\begin{tabular}{llll}
\hline Group & Participation in study & $\mathrm{n}$ \\
\hline 1 & Control Group & $\begin{array}{l}\text { Pretest, posttest, Animal Nutrition Unit } \\
\text { without mathematics integration }\end{array}$ & 71 \\
2 & Experiment Group & $\begin{array}{l}\text { Pretest, posttest, Animal Nutrition Unit } \\
\text { with mathematics integration }\end{array}$ & 85 \\
3 & Control Group & $\begin{array}{l}\text { Posttest only following Animal Nutrition Unit } \\
\text { without mathematics integration }\end{array}$ & 121 \\
4 & Experiment Group & $\begin{array}{l}\text { Posttest only following Animal Nutrition Unit } \\
\text { with mathematics integration }\end{array}$ & 139 \\
\hline
\end{tabular}

Table 2. Highest Completed Mathematics Class of Research Participants ( $\mathrm{n}=414)$

\begin{tabular}{ccc}
\hline Class & $n$ & $\%$ \\
\hline General Math & 35 & $8.4 \%$ \\
Algebra 1 & 87 & $20.9 \%$ \\
Geometry & 119 & $28.6 \%$ \\
Algebra 2 & 144 & $34.6 \%$ \\
Trigonometry & 11 & $2.6 \%$ \\
Calculus & 10 & $2.4 \%$ \\
Math 1050 Concurrent Enrollment & 8 & $1.9 \%$ \\
\hline
\end{tabular}

Table 3. Grade Reported by Participants in Highest Level Mathematics Class Completed $(\mathrm{n}=410)$

\begin{tabular}{ccc}
\hline Grade & $n$ & $\%$ \\
\hline A & 101 & $24.3 \%$ \\
A- & 45 & $10.8 \%$ \\
B+ & 47 & $11.3 \%$ \\
B & 57 & $13.7 \%$ \\
B- & 20 & $4.8 \%$ \\
C+ & 38 & $9.1 \%$ \\
C & 40 & $9.6 \%$ \\
C- & 22 & $5.3 \%$ \\
D+ & 8 & $1.9 \%$ \\
D & 15 & $3.6 \%$ \\
D- & 9 & $2.2 \%$ \\
F & 8 & $1.9 \%$ \\
\hline
\end{tabular}

4.850, $S D=2.250), t(414)=0.516, p=.935$ (two-tailed). Therefore, the researcher failed to reject the null hypothesis. Two-way analysis of variance (ANOVA) was used to determine if differences existed on the posttest mathematics performance score between the group that took both the pretest and the posttest measures and the group that took only the posttest measure. No statistically significant difference was found between the posttest scores of these groups, $F(3,412)=1.593, p$ $=.190$. There was no statistically significant difference between the control group $(M=0.140, S D=1.510)$, as compared to the mean of the experimental group $(M=$ $0.820, S D=1.760), t(154)=0.220, p=.827$ (two-tailed). Therefore, the researcher failed to reject the null hypothesis. A summary of mathematics performance gain is provided in Table 4.

Research question two sought to measure the change in self-efficacy before and after receiving a mathematics enriched animal science curriculum. There was no statistically significant difference between the mathematics self-efficacy pretest of the control group ( $M$ $=27.662, S D=5.338$ ), as compared to the mean of the mathematics self-efficacy pretest for the experimental group $(M=28.859, S D=4.577), t(151)=-1.493, p=.138$ (two-tailed). Therefore, the null hypothesis was not rejected. There was no statistically significant difference between the mathematics self-efficacy posttest of the control group $(M=27.323, S D=5.618)$, as compared to the mean of the mathematics self-efficacy posttest of the experimental group $(M=28.022, S D=6.326), t(414)=$ 1.183, $p=0.237$ (two-tailed). Therefore, the null hypothesis was not rejected.

Two-way analysis of variance (ANOVA) was used to determine if differences existed on the posttest selfefficacy score between the group that took both the pretest and posttest measures and the group that took only 
Table 4. Summary of Mathematics Performance Gain

\begin{tabular}{|c|c|c|c|c|c|}
\hline & Control Group & $\begin{array}{l}\text { Experiment } \\
\text { Group }\end{array}$ & $t$ & $p$ & $d f$ \\
\hline Pretest Raw Score & & & .082 & .935 & 154 \\
\hline Mean & 5.07 & 5.04 & & & \\
\hline Standard Deviation & 1.76 & 1.77 & & & \\
\hline Posttest Raw Score & & & .516 & .606 & 414 \\
\hline Mean & 4.96 & 4.85 & & & \\
\hline Standard Deviation & 2.10 & 2.25 & & & \\
\hline Gain Raw Score & & & .220 & .827 & 154 \\
\hline Mean & 0.14 & 0.82 & & & \\
\hline Standard Deviation & 1.51 & 1.76 & & & \\
\hline & Control Group & $\begin{array}{l}\text { Experiment } \\
\text { Group }\end{array}$ & $t$ & $p$ & $d f$ \\
\hline Pretest Self Efficacy Raw Score & & & -1.493 & .138 & 151 \\
\hline Mean & 27.662 & 28.859 & & & \\
\hline Standard Deviation & 5.338 & 4.577 & & & \\
\hline Posttest Self Efficacy Raw Score & & & -1.183 & .237 & 414 \\
\hline Mean & 27.323 & 28.022 & & & \\
\hline Standard Deviation & 5.618 & 6.326 & & & \\
\hline Self-Efficacy Gain Raw Score & & & .506 & .614 & 154 \\
\hline Mean & 0.019 & .000 & & & \\
\hline Standard Deviation & .223 & .245 & & & \\
\hline
\end{tabular}

the posttest measure. No statistically significant difference was found between the posttest scores of these groups, $F(2,412)=1.656, p=.176$. There was no statistically significant difference between the mathematics self-efficacy gain of the control group $(M=$ $0.019, S D=0.223$ ), as compared to the mean gain in mathematics self-efficacy of the experimental group ( $M$ $=.000, S D=0.245$ ), $t(154)=0.506, p=0.614$ (twotailed). Therefore, the null hypothesis was not rejected. A summary of mathematics self-efficacy gain can be found in Table 5.

To address the third research question, a Pearson correlation was used to explore the relationship between self-efficacy measures and mathematics performance. A large positive relationship (Davis, 1971) was found between mathematics self-efficacy and mathematics performance $(r=.425)$.

To address research question four, multiple regression analysis was used to determine which personal characteristics predicted mathematics self-efficacy. Characteristics included self-reported grade point average in their most recent mathematics class, highest level of mathematics completed, grade level, and gender. These factors explained $13.7 \%$ of the variance $(r=.371$; $r$ squared $=.137)$. Highest level of mathematics coursework completed $(t=5.224 ; p<.001)$ and overall grade point average $(t=4.639 ; p<.001)$ were statistically significant factors.
Multiple regression analysis also was used to determine which personal characteristics predicted mathematics performance. Mathematics self-efficacy, gender, grade level, grade point average in most recent mathematics class, and highest level of mathematics coursework completed were entered into the regression model. Just over $17 \%$ of the variance was explained by the model $(r=.414$; $r$ squared $=.171)$. Mathematics selfefficacy was the only statistically significant factor ( $t=$ 7.665; $p<.001)$.

\section{Conclusions, Discussion, and Recommendations}

The study was carried out following the conceptual model for mathematics performance and self-efficacy see (Figure 1). Mathematics performance and self-efficacy were measured prior to the unit of instruction. Mathematics was taught relevant to the subject of animal science and in context to the subject of nutrition. Finally, mathematics performance and self-efficacy were measured through the use of a posttest. Additionally, following the model of Parr et al. (2006) the majority of the research unit was based in CTE curriculum and only a small portion of the unit required the use of mathematics skills. 
There was no statistically significant difference in pretest and posttest mathematics scores when comparing the control group and the treatment group. Therefore, the researcher failed to reject the null hypothesis. Stone et al. (2008) identified one drawback to contextually based mathematics instruction. They reported that in some cases students are unable to transfer mathematics skills from one specific context to another. In this study, students were taught to mathematically balance a feed ration using the Pearson square. The Pearson square requires skills in solving basic algebraic equations, but the appearance of the mathematics problem is very different than a typical, linear algebraic equation found in a traditional mathematics class as well as on the pre- and posttest. It is possible that the lack of statistically significant change in pre- and posttest mathematics performance in this study is due to this limitation.

There was no statistically significant difference in pretest and posttest self-efficacy scores when comparing the control and treatment groups. Therefore, the researcher failed to reject the null hypothesis. Possible limitations in measuring change in self-efficacy include survey fatigue and student's inability to recognize vocabulary and terminology used in the survey. The study found a strong positive correlation between student's self-efficacy scores and their mathematics performance. These study results match those found in Howard's and Whitaker's (2008) study, which reported that students with decreased motivation had decreased mathematics skills and highly motivated students experienced success.

There were two personal characteristics among research participants that predicted mathematics selfefficacy or mathematics performance. Highest completed mathematics class and GPA in highest level mathematics class showed a large, positive correlation. Gender and grade level also were observed, and no statistically significant correlation was found. Numerous studies have historically labeled boys to be higher achievers in mathematics (McFarland et al., 2011; Pope \& Sydnor, 2010; Trusty, 2002). However, gender was not a statistically significant characteristic among the research participants. Both boys and girls performed with similar results.

Some limitations of the study include the inability to identify and monitor various external factors related to mathematics performance and mathematics self-efficacy. Significant external factors, as identified by Akerhielm (1995), include class size, socioeconomic status, and individual teacher differences. Ball (1998) discovered that teaching mathematics is more than simply adding and subtracting. Though every effort was made to create an identical learning environment in each of the eight participating schools, teacher differences still exist. Another limitation in this study is the short amount of time between the pretest, treatment, and posttest. This study measured the effects of only a single mathenhanced unit of instruction. Howard and Whitaker (2008) reported that students who struggle with mathematics could remember an exact "turning point" when the struggles began. For many students, they have struggled for years and to expect a change in attitude and performance in such little time is too optimistic. Another limitation, which could not be controlled, is the level of interest of research participants in animal science. Howard and Whitaker (2008) reported that a mathematics student who struggles needs to see the value and understand the direct application in his/her life in order to maintain a positive attitude and therefore higher mathematics self-efficacy. Interest in the subject of animal science was not measured.

Although there were no statistically significant differences between those who received the mathenhanced animal science curriculum and those who did not, teaching contextualized mathematics did not decrease participants' ability to perform mathematics or their motivation and self-efficacy in math. By incorporating mathematics throughout an entire class year, students may become more confident over a longer period of time. This change could take place due to a positive correlation between self-efficacy and mathematics performance following increased exposure to contextualized math.

Teacher educators can be encouraged to train preservice teachers to design and teach integrated curriculum across multiple subjects. Classroom teachers can learn methods of improving student motivation to learn as they present more advanced cross-curricular lessons. Administrators also can better implement the use of Professional Learning Communities, giving secondary teachers opportunities to collaborate with teachers of other subjects. For example, agriculture and other CTE instructors can improve their mathematics skills by developing contextualized mathematics and agricultural curriculum.

In future studies, it is recommended that the mathematics taught in the integrated mathematics lesson is directly transferrable to the mathematics skills required on the pre- and posttests. This additional measure will help students overcome the barrier and inability to transfer mathematics skills from one context to another and potentially provide a more accurate measurement of change before and after the treatment. Further studies should be conducted with similar lesson formats and mathematics integration, but should cover a longer length of time. Changing student perceptions and self-efficacy in math, especially for students who often struggle with mathematics, will take longer than a single unit of instruction. Additional insight could be found from a future study comparing mathematics performance and mathematics self-efficacy across CTE areas including Family and Consumer Science, Business, Health Sciences, and so forth. Another research focus could be to study the best pedagogical practices of teaching contextualized mathematics by team teaching mathenhanced agricultural curriculum with a mathematics instructor. 


\section{References}

Akerhielm, K. (1995). Does class size matter? Economics of Education Review, 14(3), 229-241. doi:10.1016/0272-7757(95)00004-4

Akinsola, M. K., \& Awofala, A. A. (2009). Effect of personalization of instruction on students' achievement and self-efficacy in mathematics word problems. International Journal of Mathematical Education in Science \& Technology, 40(3), 389404. doi:10.1080/00207390802643169

Ball, D. L. (1998). Knowledge and reasoning in mathematical pedagogy: Examining what prospective teachers bring to teacher education. Michigan State University. Retrieved from http://www-personal.umich.edu/ dball/books/ DBall_dissertation.pdf

Bandura, A. (1977). Self-efficacy: Toward a unifying theory of behavioral change. Psychological Review, 84(2), 191-215. doi:10.1037/0033-295X.84.2.191

Betz, N. E., \& Hackett, G. (1983). The relationship of mathematics self-efficacy expectations to the selection of science-based college majors. Journal of Vocational Behavior, 23, 329-345.

Campbell, D. T., \& Stanley, J. C. (1963). Experimental and quasi-experimental designs for research. Chicago, IL: Rand McNally.

Davis, J. A. (1971). Elementary survey analysis. Englewood Cliffs, NJ: Prentice Hall.

Doerfert, D. L. (Ed.) (2011). National research agenda: American Association for Agricultural Education's research priority areas for 2011-2015. Lubbock, TX: Texas Tech University, Department of Agricultural Education and Communications.

Fiore, G. (1999). Math-abused students: Are we prepared to teach them? The Mathematics Teacher, 92(5), 403-406.

Howard, L., \& Whitaker, M. (2008). Developmental students' perceptions of unsuccessful and successful mathematics learning: Developmental students' perceptions. Journal of Developmental Education, 35(2), 2-16.

King, K., Gurian, M., \& Stevens, K. (2010). Genderfriendly schools. Educational Leadership, 68(3), 38-42.

Lewin, T. (2006, November 14). As math scores lag, a new push for the basics. The New York Times, A2.

McFarland, M., Benson, A. M., \& McFarland, B. (2011). Comparing achievement scores of students in gender specific classrooms with students in traditional class. International Journal of Psychology: A Biopsychosocial Approach, 8, 99114.

National Center for Education Statistics. (2011). Mathematics 2011 State Snapshot Report. The
Nation's Report Card. Utah, Grade 8 Public Schools. Retrieved from

http://nces.ed.gov/nationsreportcard/pdf/stt2011/20 12451UT8.pdf

Pajares, F., \& Miller, M. (1997). Mathematics selfefficacy and mathematical problem solving: Implications of using different forms of assessment. Journal of Experimental Education, 65(3), 213.

Parr, B. A., Edwards, M. C., \& Leising, J. G. (2006). Effects of a math-enhanced curriculum and instructional approach on the mathematics achievement of agricultural power and technology students: An experimental study. Journal of Agricultural Education, 47(3), 81-93. doi:10.5032/jae.2006.03081

Pope, D. G., \& Sydnor, J. R. (2010). Geographic variation in the gender differences in test scores. The Journal of Economic Perspectives, 24(2), 95108. doi:10.1257/jep.24.2.95

Shinn, G. C., Briers, G. E., Christiansen, J. E., Edwards, M. C., Harlin, J. F., Lawver, D. E., ... Parr, B. A. (2003). Improving student achievement in mathematics: An important role for secondary agricultural education in the 21st Century. Unpublished manuscript. Texas A\&M University. College Station, TX. Retrieved from http://citeseerx.ist.psu.edu/viewdoc/download?doi= 10.1.1.130.5829\&rep=rep1\&type=pdf

Stevens, T., Olivarez Jr., A., Lan, W. Y., \& TallentRunnels, M. K. (2004). Role of mathematics selfefficacy and motivation in mathematics performance across ethnicity. Journal of Educational Research, 97(4), 208-221.

Stone, J., Alfeld, C., \& Pearson, D. (2008). Rigor and relevance: Enhancing high school students' math skills through career and technical education. American Educational Research Journal, 45(3), 767-795. doi:10.3102/0002831208317460

Stone, J., \& Hansen, H. (2007). Making math work. Principal Leadership: High School Edition, 7(5), 43-45.

Tews, N. M. (2011). Integrated curricula: Implementing English and math credit into CTE. Techniques: Connecting Education \& Careers, 86(1), 44-47.

Trusty, J. (2002). Effects of high school course-taking and other variables on choice of science and mathematics college majors. Journal of Counseling \& Development, 80(4), 464-474.

Young, R. B., Edwards, M. C., \& Leising, J. G. (2009). Does a math-enhanced curriculum and instructional approach diminish students' attainment of technical competence? A year-long experimental study in agricultural power and technology. Journal of Agricultural Education, 50(1), 116-126. doi:10.5032/jae.2009.01116 